\title{
Improvement of Heavy Oil Recovery in the VAPEX Process using Montmorillonite Nanoclays
}

\author{
K. Pourabdollah'*, A. Zarringhalam Moghaddam², R. Kharrat ${ }^{3}$ and B. Mokhtari' \\ 1 Department of Chemical Engineering, Shahreza Branch, Islamic Azad University, Shahreza - Iran \\ 2 Chemical Engineering Faculty, Tarbiat Modares University, Tehran - Iran \\ 3 Petroleum University of Technology Research Center, Tehran - Iran \\ e-mail: pourabdollah@iaush.ac.ir - zarrin@modares.ac.ir -kharrat@put.ac.ir -mokhtari.bahram@gmail.com \\ * Corresponding author
}

\begin{abstract}
Résumé - Amélioration de la récupération d'huile lourde par utilisation de nanoargiles de Montmorillonite dans le procédé VAPEX - Dans cet article, on décrit l'utilisation de particules de nanoargile en tant qu'adsorbant mobile dans des réservoirs d'huile afin d'adsorber les asphaltènes, réduire la viscosité de l'huile et renforcer la dispersion. L'objectif de cet article consiste en la description d'une étude expérimentale de récupération améliorée d'huile lourde par l'utilisation de nanoparticules in situ. Ce qui constitue une première. En outre, deux méthodes d'analyse thermique (thermogravimétrie et analyse thermique différentielle) ont été utilisées pour analyser la teneur en asphaltène des résidus d'hydrocarbures dans les chambres balayées au cours des procédés VAPEX nano-assisté et conventionnel. Les expériences ont été réalisées en utilisant une huile lourde iranienne et du propane : le dispositif expérimental consistait en deux cellules garnies de sable, l'une garnie uniquement avec des billes de verre en tant que milieu poreux et l'autre avec des billes de verre et de la montmorillonite modifiée en tant que nanoargile ; les deux avaient la même porosité et la même perméabilité. La teneur en asphaltène déposé dans les zones balayées, le profil de propagation des chambres de vapeur ainsi que les taux de consommation de solvant et de production d'huile ont été déterminés. Les résultats ont mis en évidence que la montmorillonite a modifié l'hétérogénéité du milieu poreux et a conduit à former des percées accrues, à augmenter la surface interfaciale solvant/bitume et à accélérer la production d'huile. Il s'est avéré que non seulement le débit d'injection de solvant a été diminué, mais que la récupération d'huile lourde a également été sensiblement accrue de $30( \pm 4) \%$.
\end{abstract}

\footnotetext{
Abstract - Improvement of Heavy Oil Recovery in the VAPEX Process using Montmorillonite Nanoclays - In this paper, the nanoclay particles were introduced as mobile adsorbents in oil reservoirs to adsorb the asphaltenes, reduce the viscosity and enhance the dispersion. The objective of this paper is experimental investigation of enhanced heavy oil recovery using in situ nanoparticles for the first time. Moreover, two thermal analysis methods (thermogravimetry and differential thermal analysis) were used to analyze the asphaltene content of residue hydrocarbons in the swept chambers in nano-assisted and conventional VAPEX processes. Experiments were carried out using Iranian heavy oil and propane: the setup consisted of two sand-packed cells; one packed only with glass beads as the oil matrix and the other
} 
with glass beads and modified montmorillonite as the nanoclay, while they had similar porosity and permeability. The content of deposited asphaltene in swept matrixes, the propagation pattern of vapor chambers in heavy oil matrixes, and the rates of solvent consumption and oil production were determined. The results elucidated that montmorillonite changed the matrix heterogeneity and led to forming enhanced breakthroughs, to increasing the interfacial surface of vapor/bitumen and to accelerating the oil production. It was found that not only was the rate of vapor injection diminished, but the heavy oil recovery was also markedly enhanced by $30( \pm 4) \%$.

\section{INTRODUCTION}

\section{The Importance of the VAPEX Process}

The resources of heavy oil in the world are more than twice those of conventional light crude oil. Saniere et al. illustrated that from the available heavy oil only a fraction is extracted by conventional methods [1]. Figure 1 shows the worldwide heavy oil resources and production.

The quota of high-viscosity oil in total worldwide oil production is constantly growing. Large reserves of high-viscosity oils are found in Canada, Venezuela, Mexico, the USA, Russia, Kuwait and China [2]. Average heavy oil production is now about $12 \%$ of total world oil production [3]. Different categories of heavy crude are usually defined according to their density and viscosity, as illustrated in Figure 2. Heavy oils, which often result from bacterial oxidation of conventional oils inside the reservoir rock, have different physical and chemical properties, generally degraded: they have much higher viscosity, higher heavy metals and higher sulfur and nitrogen contents [4]. To reduce the viscosity, solvents are frequently used to dilute heavy crudes. This is one of the most efficient methods in pipeline transportation of heavy oils. Solvents are also injected into the reservoir for well cleaning, stimulation, fracturing and, less frequently, for miscible displacement [5].
A large amount of heavy oil is still trapped in reservoirs after the traditional oil extraction, thus a number of enhanced heavy oil recovery processes have been developed for extracting the residual heavy oil [6].

Enhanced recovery processes for heavy oil are mainly thermal, solvent-based and cold methods. In thermal methods such as Steam-Assisted Gravity Drainage (SAGD), Combustion Overhead Gravity Drainage (COGD), Cyclic Steam Stimulation (CSS) and In Situ Combustion (ISC) or Toe-to-Heel Air Injection (THAI), the viscosity is reduced by heating the reservoir, but the major problem is the heat loss to adjacent formations. In cold methods such as Cold Heavy Oil Production with Sands (CHOPS), water flooding, surface mining and Gas-Assisted Gravity Drainage (GAGD), there is no solvent or thermal consumption. However, solvent-based methods such as Vapor Extraction (VAPEX) and the Solvent-Aided Process (SAP) are preferred. Recently, some interesting techniques and hybrid methods have been patented such as combined Steam And Vapor Extraction (SAVEX) and Radiofrequency-Assisted Gravity Drainage (RASD) [7].

Abu-Khader defined the asphaltene constituents as a solubility class that was precipitated from petroleum, heavy oil and bitumen by the addition of an excess of a liquid paraffin hydrocarbon [8]. Mousavi-Dehghani reported many factors which affect the asphaltene precipitation
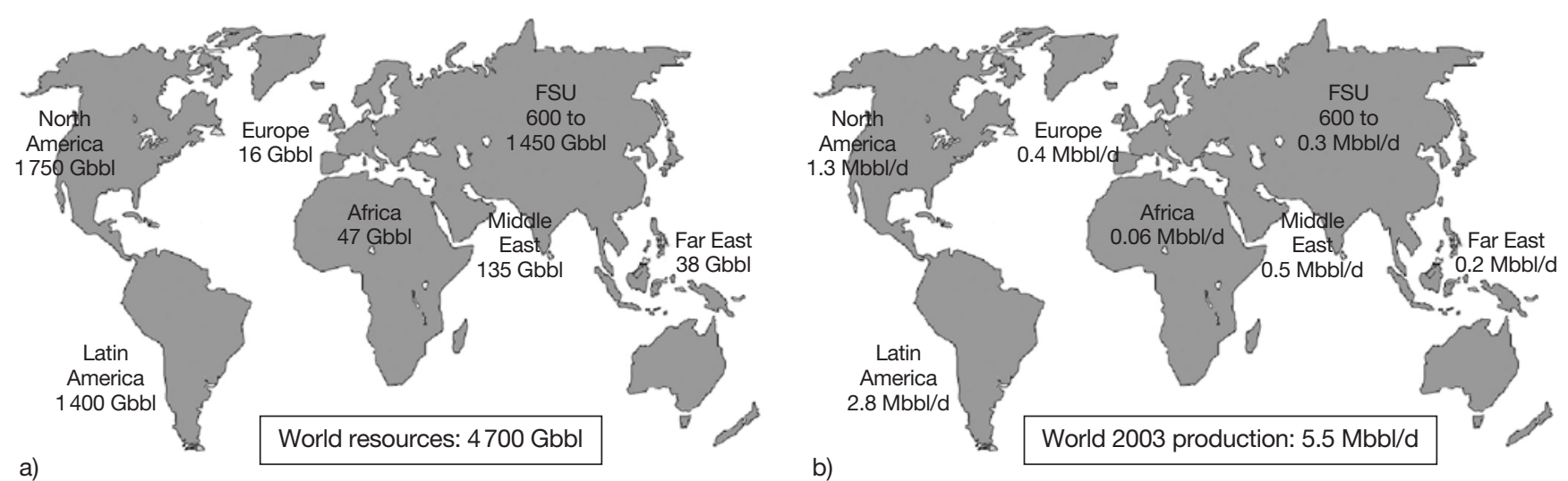

Figure 1

Geographical distribution of heavy oil resources a) and its production b). 


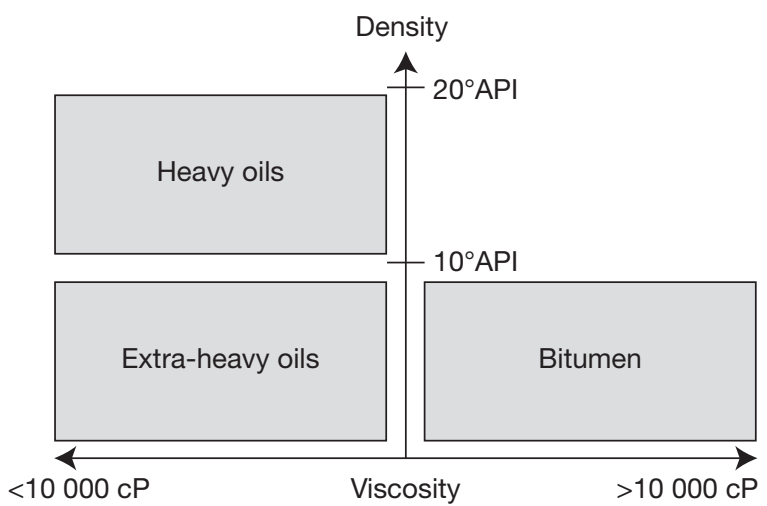

Figure 2

Schematic classification of heavy oils.

inside a reservoir [9]. Das and Butler [10] and Kök et al. [11] analyzed the asphaltene deposition by the VAPEX process in a Hele-Shaw cell, while this work was carried out in sand-packed cells. Moreover, the asphaltene movement and its distribution were studied during the experiment run.

\section{The Importance of Nanoclays}

The advantage of nanoparticles with respect to their application is attributed to their nano-size, which strongly affects the property changes in the bulk material. Depending on the academic source, there are four main groups of clays: kaolinite, smectite, illite and chlorite. The term of nanoclay is attributed only to the smectite family, which has a unique morphology, featuring one dimension in the nanometer range. Therefore, kaolinite, illite and chlorite are not included as nanoclays. Montmorillonite (MMT), a member of the smectite family, was discovered in 1847 in Montmorillon in the Vienne prefecture of France, more than 50 years before the discovery of bentonite in the US. MMT is 2:1 clay, meaning that it has 2 tetrahedral sheets sandwiching a central octahedral sheet. The particles are plate-shaped with an average diameter of approximately one micrometer. Individual platelet thicknesses are just one nanometer, but surface dimensions are generally 300 to more than 600 nanometers, resulting in an unusually high aspect ratio.

A characteristic of MMT nanoclays, which makes them special, is their interaction with the surrounding matrix. This special interaction is based upon their modification method and modifiers. MMTs with different structures reveal different reactivity and hence, their modifications are varied. Therefore, special characteristics of MMTs are dependent on their structure, reactivity and modifiers, which are discussed in the following.

\section{The Structure of MMTs}

As discussed above, according to Figure 3, MMT is one of the smectite group, composed of silica tetrahedral sheets layered with an alumina octahedral sheet [12]. The imperfections of the MMT crystal lattice with the isomorphous substitution induce a net surface negative charge that leads to the adsorption of metals, cations and sulfur atoms in the interlayer space and external surfaces. MMT also contains dangling hydroxyl end-groups on the surfaces and has a large specific surface area; it exhibits good adsorbability [13].

\section{MMT's Reactivity}

Masih et al. investigated the affinity of $\mathrm{Na}^{+} \mathrm{MMT}$ with the modifier arsenic by preparing different types of iron species [14]. There have been other studies conducted on the cation exchange capacity of MMT [15]. Navratilova et al. studied adsorption of two cationic surfactants, hexadecyl trimethyl

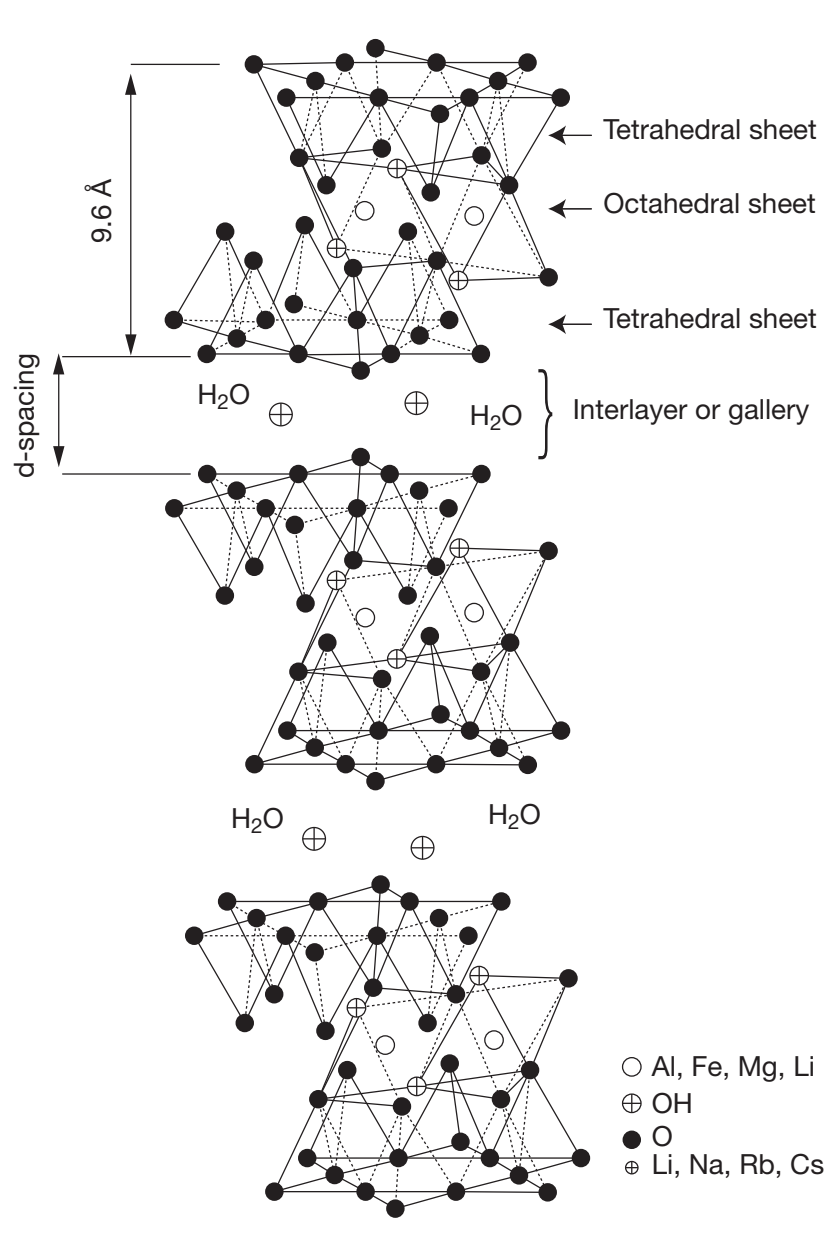

Figure 3

Schematic presentation of Montmorillonite structure. 
ammonium bromide and benzyl dimethyl hexadecyl ammonium chloride, onto the samples of MMT [16]. Fusova investigated the intercalation of octadecylamine into the interlayer space of MMT in relation to the quantity of added organic substance [17]. Therefore, organically modified MMTs have become an attractive class of organic/inorganic hybrids because of their potential use in a wide range of applications [18].

\section{Modified MMTs}

The adsorption hypothesis of modified MMT has been reported by Lin et al. [19] and Rahman et al. [20] for adsorption of Bovine Serum Albumin (BSA) protein and crude oil into the layered silicate MMT. Based upon Lin et al.'s [19] suggested mechanism, the modified MMTs is prone to adsorbing heavy oil asphaltenes and their micelles in their interlayer spaces. Therefore, this tendency of MMTs to adsorb the heavy oil asphaltenes was used to improve the rate of the VAPEX process [21]. Figure 4 illustrates schematically the asphaltene substitutions into the layered $\mathrm{Na}^{+} \mathrm{MMT}$.

Based upon these methods, in the present study MMTs with $d$-spacing of $3.15 \mathrm{~nm}$ were used in order to adsorb asphaltene into the MMT's spaces. The effects of MMTs on the pattern and content of asphaltene adsorption and upgrading, the propagation pattern of the vapor chamber in a heavy oil matrix, the rates of vapor consumption and oil production, and the recovery factor were studied by comparing two systems, with and without MMTs.

\section{Thermal Analysis of Crude Oil}

Nowadays, much research is done to analyze the crude oil components such as asphaltenes. In this regard, thermal analysis has provided useful data [22-24]. Thermal analysis is a group of instrumental methods for evaluating different properties and the chemical composition of complex materials by heating the sample at a given rate (normally 10 $50^{\circ} \mathrm{C} / \mathrm{min}$ ) at different pressures and compositions of the gas medium. Thermogravimetry (TG), Differential Scanning Calorimetry (DSC) and Differential Thermal Analysis
(DTA) are the major methods in this field, in which certain parameters (e.g. the amount of absorbed/released heat) as a function of the temperature is recorded. Heating the heavy oil multicomponent system results in evaporation of first, light naphtha-ligroin cuts (up to $200^{\circ} \mathrm{C}$ ), then kerosene-gasoil cuts $\left(200-300^{\circ} \mathrm{C}\right)$, and finally, lube oil cuts $\left(>300^{\circ} \mathrm{C}\right)$. The different vaporizability of the heavy oil components is the basis of quantitative and qualitative evaluation of the properties of a given component.

Kök et al. [25] determined the Saturate, Aromatic, Resin and Asphaltene (SARA) fractions as well as their kinetic parameters in medium and heavy crude oils using thermogravimetric analysis and air atmosphere at a $10^{\circ} \mathrm{C} / \mathrm{min}$ heating rate. Karacan and Kök [26] examined the pyrolysis behavior of crude oils and their fractions using DSC and TG and a $10^{\circ} \mathrm{C} / \mathrm{min}$ heating rate under nitrogen atmosphere. They revealed that pyrolysis mechanisms depend on the chemical nature of the constituents. In another paper, Kök and Okandan [27] investigated the thermal characterization of crude oil using DSC. Moreover, they studied the effect of reaction temperatures and higher heat flow rates.

The aim of this work was to study the enhanced heavy oil recovery using in situ modified MMTs. The experiments focused on the nano-assisted dispersion, hence the setup conditions were designed in such a way that the competition phenomena such as de-asphalting were diminished. The effect of MMTs on improvement of the recovery factor and production rate was studied in two systems, one with MMTs and the other without MMTs.

\section{EXPERIMENTAL METHOD}

\subsection{Materials}

The MMT particles were purchased from Southern Clay Products and their physical properties are summarized in Table 1. The tested bitumen was sampled from the Sarvak formation of the Kuh-e-Mond Reservoir in the south of Iran (Tab. 2 shows its composition). Propane with $99.5 \%$ purity at $827 \mathrm{kPa}$ (its dew point) was selected as the solvent since it

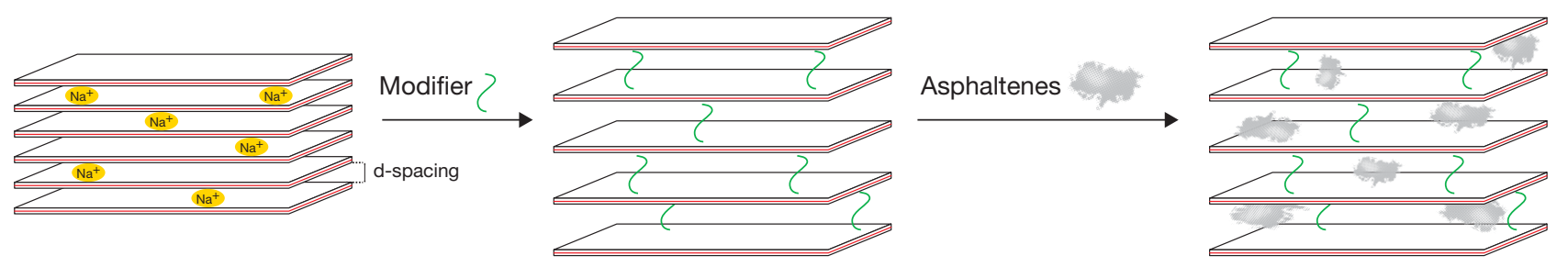

Figure 4

The asphaltene depositions into the layered $\mathrm{Na}^{+} \mathrm{MMT}$. 
has a lower dew point pressure than methane and ethane and allows the experiments to be conducted at lower operating pressures. In addition, the amount of de-asphalting is higher with propane than with butane and pentane. Porous media was made in a sand-packed cell using glass beads.

TABLE 1

Physical properties of MMT nanoclay

\begin{tabular}{l|l}
\hline Properties & Value \\
\hline Specific gravity & $1660 \mathrm{~kg} / \mathrm{m}^{3}$ \\
\hline Bulk density & $172.9 \mathrm{~kg} / \mathrm{m}^{3}$ \\
\hline X-ray diffraction $d$-spacing $(001)$ & $3.15 \mathrm{~nm}$ \\
\hline Modifier concentration, meq $/ 100 \mathrm{~g}$ clay & 125 \\
\hline Organic modifier & $\begin{array}{l}\text { Dimethyl dihydrogenated } \\
\text { Tallow quaternary ammonium }\end{array}$ \\
\hline
\end{tabular}

TABLE 2

Characteristics of flashed heavy oil

\begin{tabular}{l|c|c}
\hline Composition & Flashed oil & Unit \\
\hline $\mathrm{N}_{2}$ & 0.00 & $\mathrm{~mol} \%$ \\
\hline $\mathrm{CO}_{2}$ & 0.00 & $\mathrm{~mol} \%$ \\
\hline $\mathrm{C}_{1}$ & 0.00 & $\mathrm{~mol} \%$ \\
\hline $\mathrm{C}_{2}$ & 0.08 & $\mathrm{~mol} \%$ \\
\hline $\mathrm{C}_{3}$ & 0.12 & $\mathrm{~mol} \%$ \\
\hline $\mathrm{C}_{4}-\mathrm{C}_{5}$ & 7.76 & $\mathrm{~mol} \%$ \\
\hline $\mathrm{C}_{6}-\mathrm{C}_{11}$ & 14.51 & $\mathrm{~mol} \%$ \\
\hline $\mathrm{C}_{12}{ }^{+}$ & 77.53 & $\mathrm{~mol} \%$ \\
\hline Asphaltene content & 32.30 & $\mathrm{wt} \%$ \\
\hline Resin content & 3.21 & $\mathrm{wt} \%$ \\
\hline
\end{tabular}

\subsection{Methodology to Spike the MMT Nanoclays into the Glass-bead Matrix}

Although many procedures have been suggested to coat the granular glass beads, the spraying method was chosen in these laboratory tests. Figure 5 presents schematically the spraying method to spike MMT particles into the glass beads. The suspension of $1.00 \mathrm{~g}$ modified MMT in $100 \mathrm{cc}$ volatile condensate was prepared and was sprayed into the rotary mixer. The mixing time was selected to be $30 \mathrm{~min}$ (until the condensate was evaporated). Figure 6 shows the SEM image of coated glass beads. According to Figure 6, the MMT particles (white dots) were placed around the glass beads. The doped glass-bead particles were sieved and the required sizes $(212-300 \mu \mathrm{m})$ were chosen. The density and the permeability of glass beads were determined to be $2530 \mathrm{~kg} / \mathrm{m}^{3}$ and $25-30$ $\mathrm{D}$, respectively.

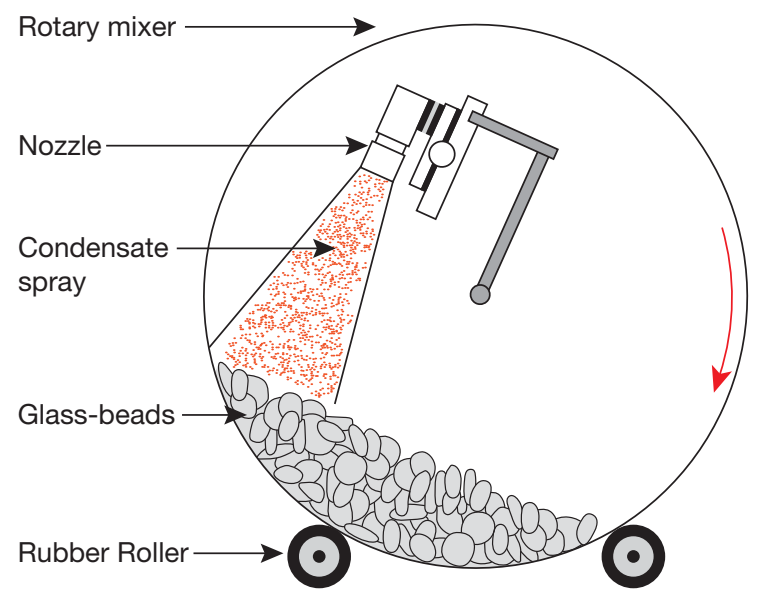

Figure 5

Schematic presentation of spiking the MMT nanoclays into the glass beads media.

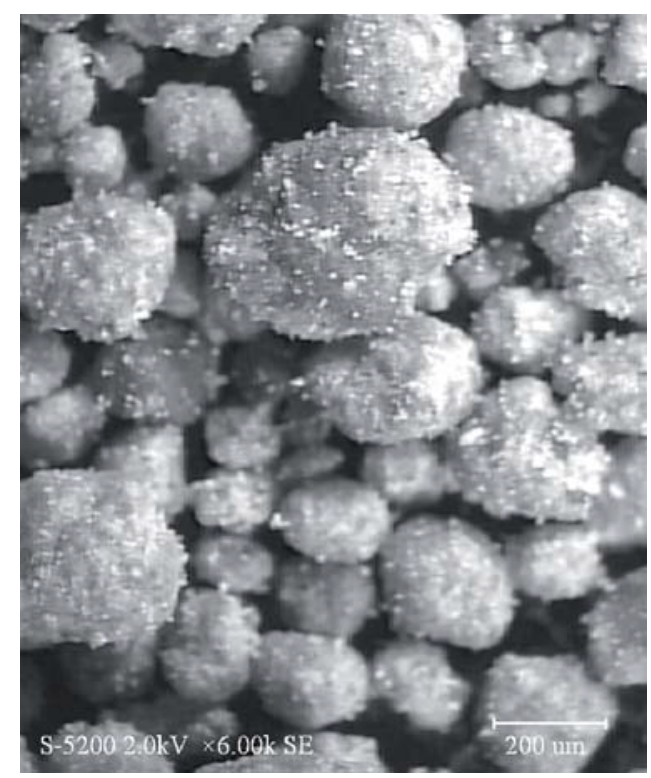

Figure 6

The SEM image of doped glass beads with MMT particles (before sieving).

\subsection{Apparatus and Setup}

The flow diagram of the experimental setup is schematically illustrated in Figure 7. The VAPEX cell was a three-dimensional rectangular visual model as a symbol of a reservoir cross-section with $673 \times 153 \times 31 \mathrm{~mm}$ dimensions and 3300 cc volume, containing 5, 3 and 2 ports at the bottom, top and 


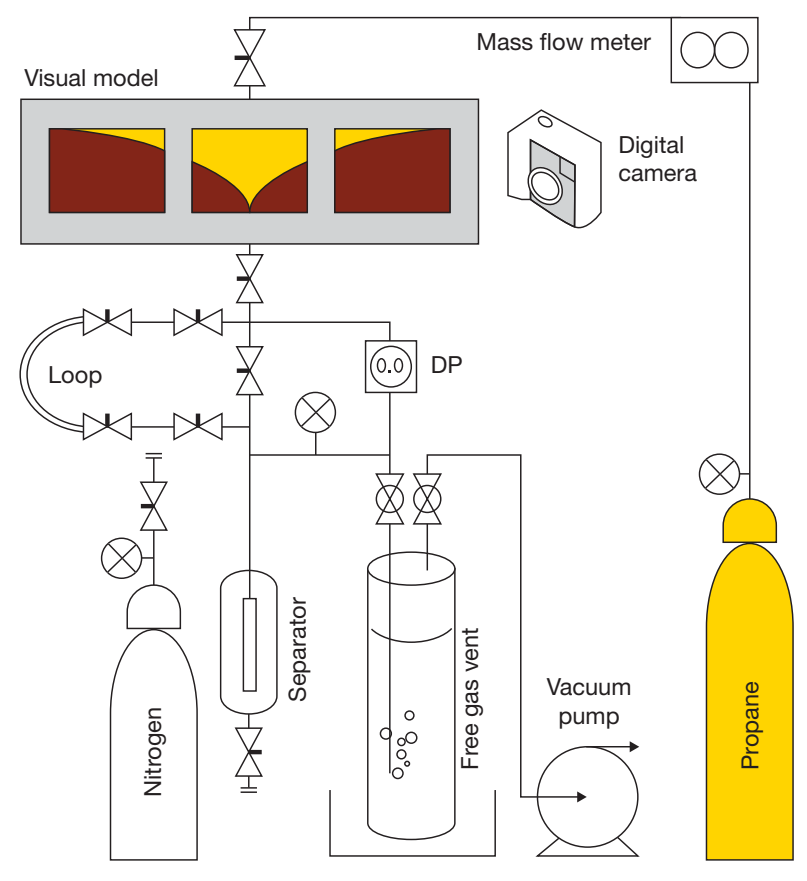

Figure 7

Schematic illustration of flow diagram in the VAPEX experimental setup.

on both sides, respectively. This model represents a thin slice of the reservoir (two-dimensional rectangle) that is perpendicular to the horizontal well pair. A Plexiglas window allowed the operator to monitor the shape of the swept zone.

The mass flow meter was calibrated using a nitrogen gas/gas accumulator vessel and the system was examined for leakage by nitrogen gas at $1034 \mathrm{kPa}$ pressure to pack the cell. The cell was depressurized and the cavity of the model was packed uniformly with the doped glass beads by shaking the model. The doped glass beads were transferred to the cavity of the first cell via one aperture on the side of the body and were shaken for about $60 \mathrm{~min}$, simultaneously. The second cell was packed without MMTs. The absolute porosities of the two cells were calculated and found to be $36.2( \pm 0.1) \%$ and $36.9( \pm 0.1) \%$ for three replications, respectively. Subsequently, the sand-packed model was saturated with preheated bitumen at $80^{\circ} \mathrm{C}$ for $12 \mathrm{~h}$ and was allowed to cool (to room temperature).

\subsection{The VAPEX Methodology}

The separator was pressurized by nitrogen gas at $827 \mathrm{kPa}$. Afterwards, propane was injected into the injection well at the top of the model. The flow rate of injected gas was measured using a calibrated mass flow meter, while the ambient temperature was set and kept at $22( \pm 0.5)^{\circ} \mathrm{C}$. The amount of live oil accumulated was monitored through the separator by a calibrated, graduated, site glass. While the oil samples were being obtained, most of the solution gas was liberated due to pressure reduction and directed to the accumulated solution gas in the vessel. After collecting the sample, the rate of free gas production was controlled by a needle valve to be $11 \mathrm{cc} / \mathrm{min}$. During the experiment, a digital camera recorded all visible changes in the solvent chamber. The experiments were run continuously for $21 \mathrm{~h}$. After the test run, the systems were depressurized; the glass beads were sampled from both the gas and bitumen chambers of the two cells. Samples were taken from 35 locations on the model by a test tube.

\subsection{Chemical Analysis}

The samples were weighed by a calibrated Mettler Toledo digital balance and were placed into a Lindberg furnace (Sola Basic) for about $4 \mathrm{~h}$ at $600^{\circ} \mathrm{C}$ to eliminate residual bitumen. After cooling, the glass beads were weighed again and the weight loss was measured for each sample. The weight loss represented the crude distribution at different points of both chambers. Asphaltenes were determined in the samples from thirteen locations in the vapor chamber. Then, the samples were analyzed via the ASTM D1548 standard test method and thermal analysis. For each test, three measurements were performed and Relative Standard Deviations (RSD) were calculated to be less than $3 \%$.

\subsection{Thermal Analysis}

In order to run the thermal analysis, matrix samples of very low weights (of the order of 8-10 mg), which increased the quality of the thermograms, were used. The samples were heated in an air atmosphere at the rate of $10^{\circ} \mathrm{C} / \mathrm{min}$. The weight losses of samples were recorded, while the temperature was raised. After the given temperature, the weight loss on an ordinary analytical balance was determined. The operation was repeated with another sample from the matrix doped with MMTs. After that, the required curves were plotted in weight percent versus standard temperature $\left({ }^{\circ} \mathrm{C}\right)$ coordinates. The DTA curve was also recorded on a scanning calorimeter and the resulting graphs were recorded similarly.

\section{RESULTS AND DISCUSSIONS}

\subsection{Distribution of Asphaltenes and Resins}

In the VAPEX experiments with and without MMTs, the asphaltene concentrations at different points of the two cells were determined and the results are presented in Figure 8.

Figure 8 shows the same pattern of asphaltene precipitation from injection to the production wells in both the nanoassisted and conventional VAPEX processes. At the oil-solvent interface, diffusion of solvent into the oil bulk led to 
formation of asphaltene micelles, which tended to be adsorbed on the surrounding sides (glass beads or solid particles).

According to Figure 8, two comparative adsorption phenomena are active in the media; adsorption of asphaltene particles by MMTs and deposition of asphaltenes on the matrix surfaces, whose contents were calculated by comparing the remaining asphaltenes in both cells to be in the range of 40$48 \%$ of total precipitated asphaltenes, which were the main portion of precipitated asphaltenes.

As discussed before, the MMT crystal lattice induced a net surface negative charge (dangling hydroxyl end-groups) that led to the adsorption of metal, cation and sulfur atoms in the interlayer spaces and external surfaces. These negative charges navigate the adsorption of asphaltene as well as the penetration of resins into the interlayer spaces of the MMT's structure. Figure 9 shows the pattern of resin distribution in the swept zone.

In addition, the results showed that the asphaltene content of the produced oil was markedly lower when MMTs were used. This revealed that more asphaltenes remained in the matrix and the quality of the produced oil was enhanced. The formation damage which is caused by asphaltene deposition can be removed by washing.
Furthermore, the content of residual asphaltene in the swept zone (vapor chamber) is more than the bitumen chamber. The asphaltene distribution is not uniform in the swept zone. Its concentration around the injection well is maximum, while around the production well and both sides it is minimum. Around the injection well, the concentration gradient between solvent and bitumen increases and thereby the mass transfer is enhanced. Hence, more asphaltene will be precipitated. Far from this zone, the reduction of solvent concentration leads to a decrease in the concentration gradient and decline in the asphaltene deposition. Therefore, the precipitated asphaltene decreases markedly around the production well.

\subsection{Interpretation of TG/DTA Curves}

Figure 10 shows the combined TG/DTA curves of residue hydrocarbons coating the glass beads.

As the temperature rose, first the residual light cuts including light naphtha, kerosene and gasoil evaporated from the sample. This is between ambient temperatures and $200^{\circ} \mathrm{C}$, which is not shown in the figure. Then, higher cuts including n-paraffins, light oil cuts, paraffin-naphthenes, naphtheneparaffins and polycyclic aromatic compounds were oxidized.

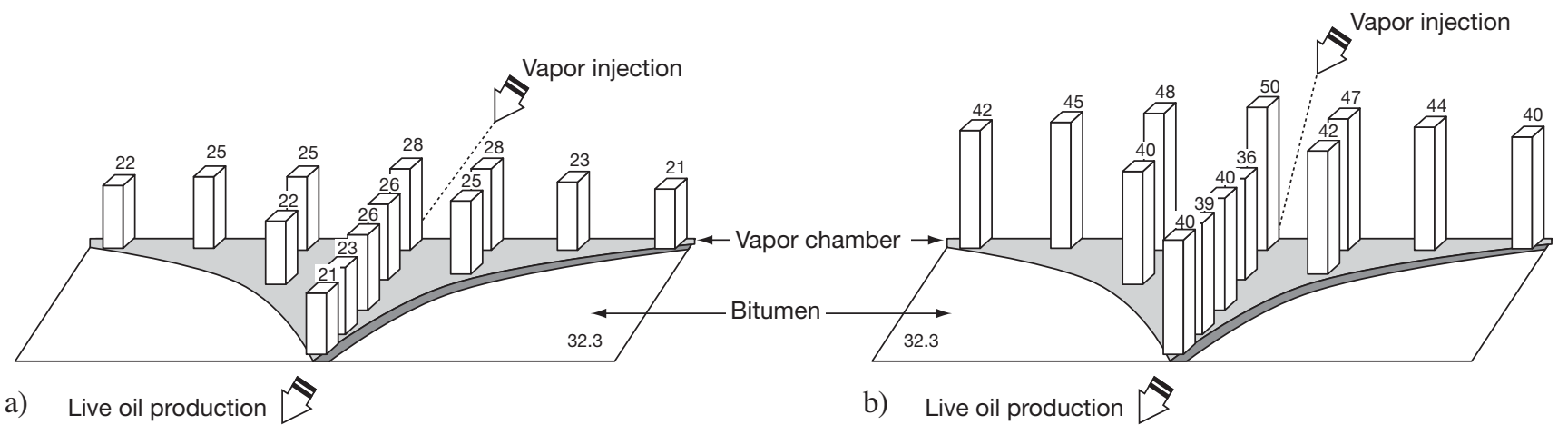

Figure 8

The percent of asphaltene content in residue hydrocarbons at different points of the solvent chamber:

a) the conventional VAPEX cell without MMTs and b) the nano-assisted cell with MMTs.

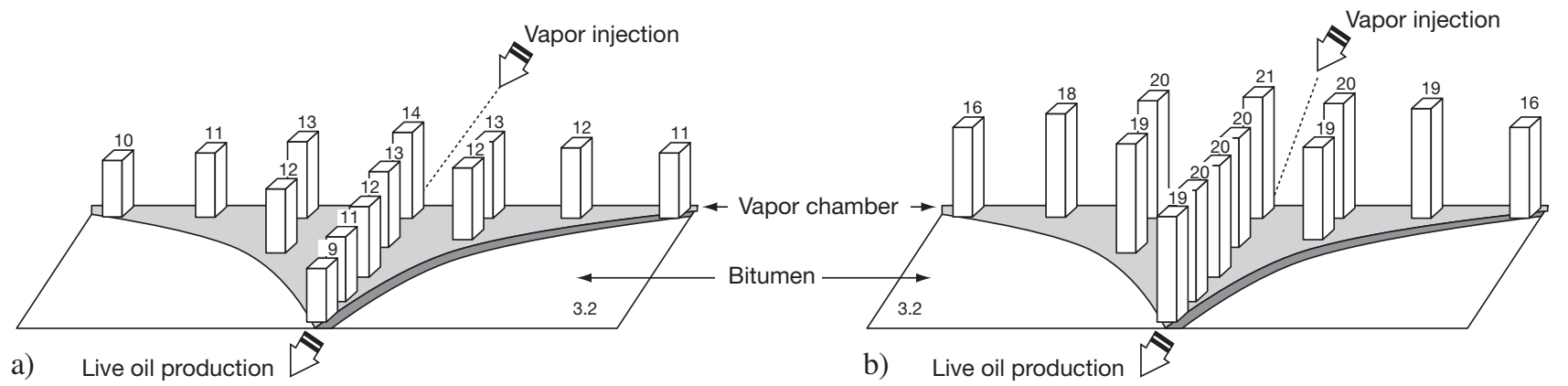

Figure 9

The percent of resin content in residue hydrocarbons at different points of the solvent chamber: a) the conventional VAPEX cell without MMTs and b) the nano-assisted cell with MMTs. 

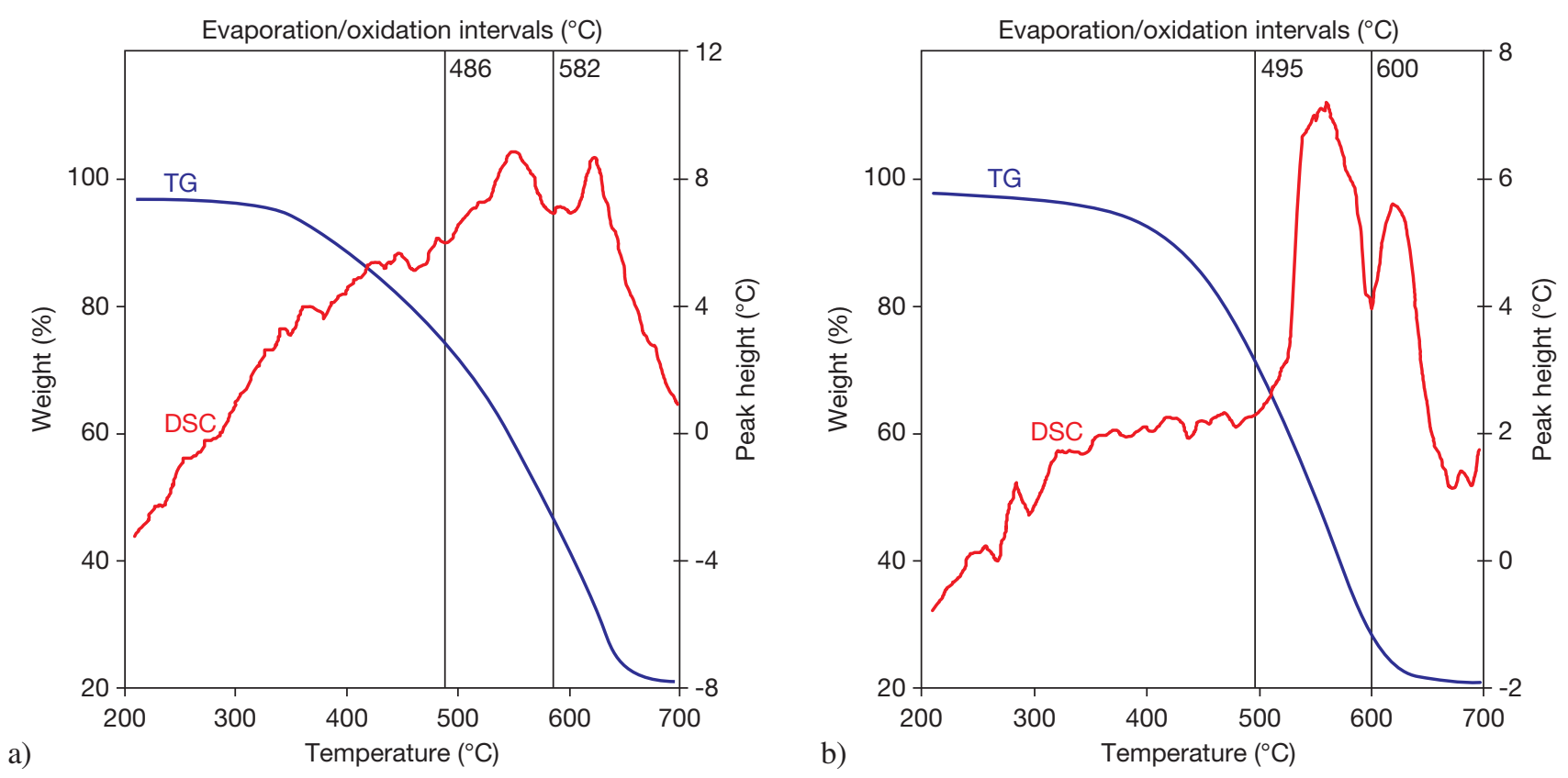

Figure 10

The TG and DTA curves of residue hydrocarbons (top of the vapor chambers): a) Without MMTs and b) with MMT nanoclays.

The oxidization took place without significant thermal effects. Evaporation and oxidation of these cuts were completed at $400^{\circ} \mathrm{C}$. The resins, asphaltenes and carbenes were oxidized above 400,500 and $600^{\circ} \mathrm{C}$, respectively.

As shown in Figure 10, there are two vertical isothermal lines in the diagrams, which divide them into three segments including the loss of light (distillate) cuts, resins, asphaltenes and carbene-based cuts. In the figure, the reference temperature is plotted on the $X$-axis, the weight loss on the left ordinate, the DTA peak height on the right ordinate and the evaporation and oxidation intervals in the first line above the curves.

The left figure shows that by $486^{\circ} \mathrm{C}$, the sample loses 28 percent of its weight due to the light distillate portion of the crude and oxidation of resins. At $486^{\circ} \mathrm{C}$, an exothermic effect on the DTA curve appears, signaling the beginning of oxidation of the crude oil asphaltenes. Similarly, in the right figure by $495^{\circ} \mathrm{C}$, the sample loses 28 percent of its weight due to the light distillate portion of the crude, without noticeable heat effects on the DTA curve. At $495^{\circ} \mathrm{C}$, a sharp exothermic effect on the DTA curve depicts the beginning of asphaltene oxidation in the crude oil heavy residue.

The heat evolution continues with varying degrees of intensity until $700^{\circ} \mathrm{C}$ when finally the entire crude oil heavy residue in the crucible is volatilized and oxidized. The first cut (left segment) revealed the evaporation and oxidation of distillates and resins. The second cut (between isothermal lines) is related to oxidization of asphaltenes, while the loss (burning) of carbenes occurred in the third segment. The weight loss of the TG curve in this middle segment was attributed to the asphaltene content of samples. This procedure can be repeated for the other segments. The asphaltene contents of residue hydrocarbons in the conventional and nano-assisted VAPEX cells were determined to be 28 and $46 \%$, respectively. This was confirmed by the reference method of ASTM D-1548.

\subsection{Propagation of Vapor Chamber}

The photographs in Figure 11 present a snapshot of the experiments after $9 \mathrm{~h}$. During the VAPEX process, diffusion of solvent dilutes a thin section of bitumen and the diluted live oil drains into the production well. The solvent interacts with bitumen at the horizontal edge on the upper side of the model. The solvent chamber forms and the spreading phase begin and continue up to the end of the 21-h-long experiment.

The picture at the right side of Figure 11 shows the spreading stage using MMTs, while the picture on the left is related to the spreading stage without using MMTs. By comparing the pictures, it can be seen that in the presence of MMTs, the number of breakthroughs is more. By increasing the number of breakthroughs, the contact area between the solvent and oil was increased and the vapor diffusion rate and the production rate as well as the recovery factor were enhanced, respectively. Such a pattern continued up to the end of the test. 

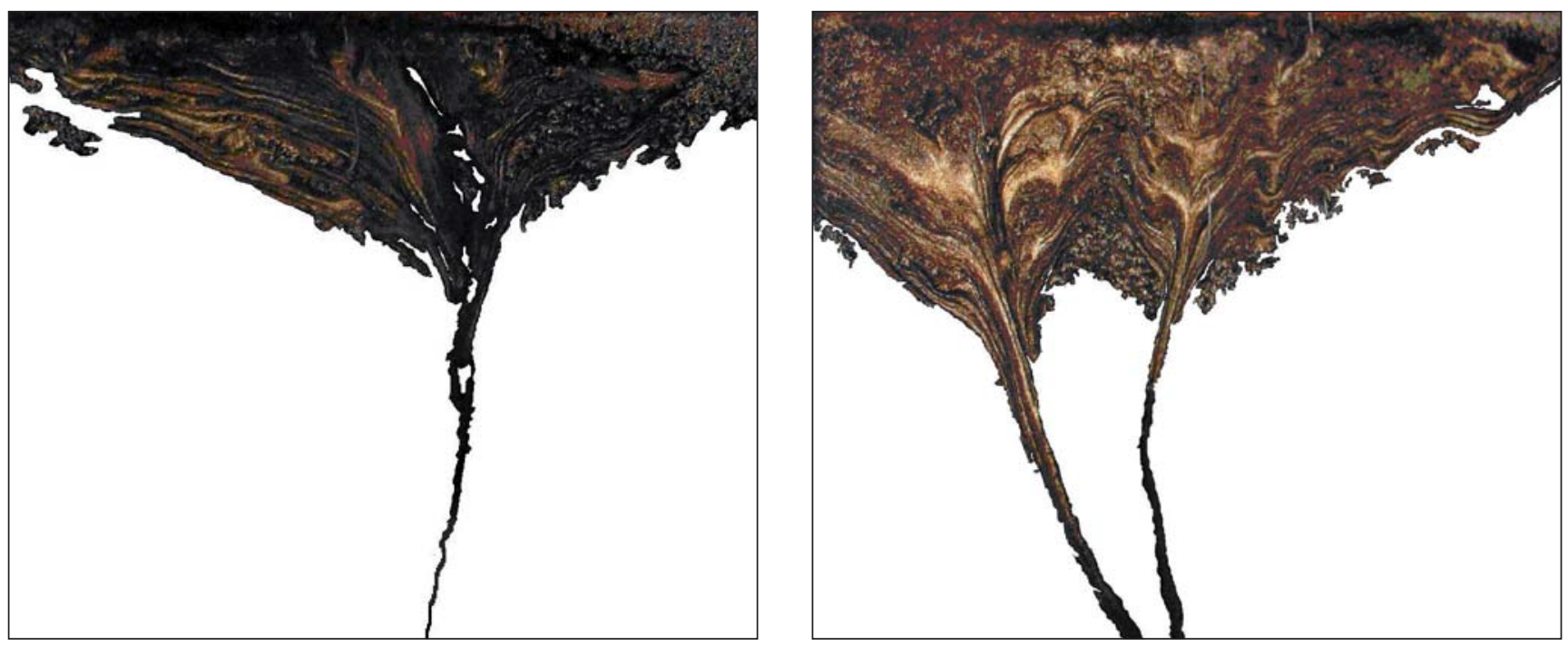

Figure 11

Presentation of spreading stage of solvent chamber without MMTs (left) and using MMTs (right) after $9 \mathrm{~h}$.

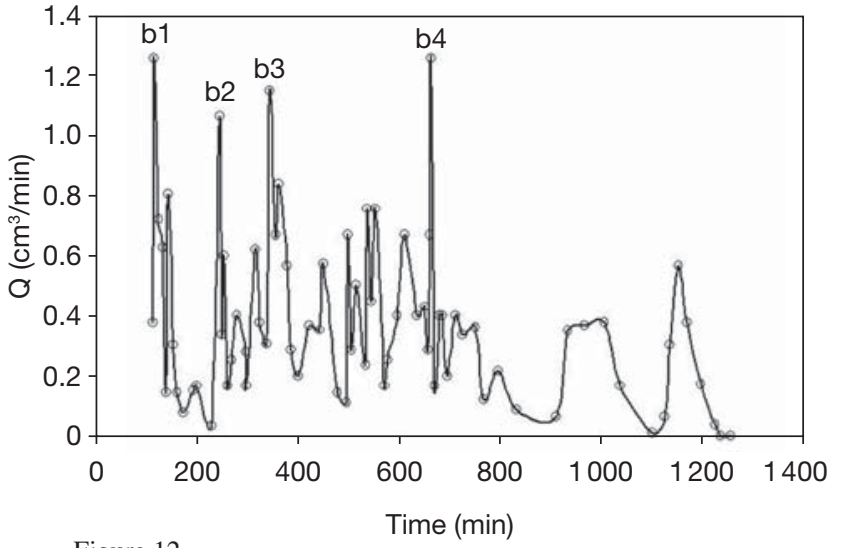

Figure 12

The breakthrough peaks in the presence of MMTs. $b_{n}$ indicates the number of breakthroughs.

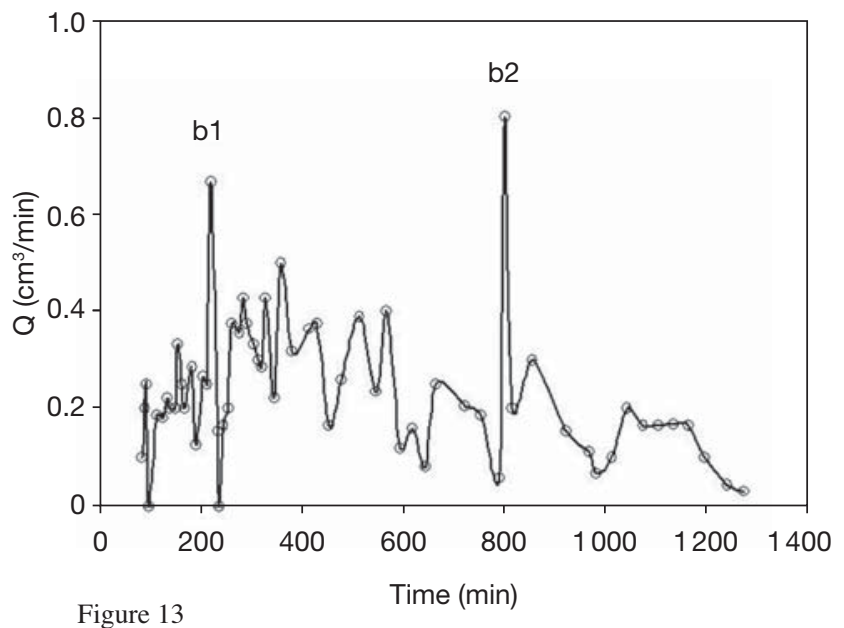

The breakthrough peaks in the absence of MMTs. $b_{n}$ indicates the number of breakthroughs.
Figures 12 and 13 present the flow fluctuations in nanoassisted and conventional VAPEX processes, respectively. The high fluctuations represent the breakthrough formation during the experiments.

The peaks denoted with the letter $b$ are related to breakthroughs. As can be seen from Figures 6 and 7, the numbers of breakthrough peaks in the presence of MMTs are more and their intensity is higher. Furthermore, the lower concentration of asphaltene in the oil lowers the viscosity, making the oil more susceptible to breakthrough.

\subsection{The Recovery Factor}

In Figure 14, the oil recovery results from VAPEX experiments with and without MMTs are presented. It can be seen that higher recovery was demonstrated with nano-assisted experiments; MMTs improved both the recovery factor and production rate in the VAPEX process by a factor of $30( \pm 4) \%$.

Analysis of variance (ANOVA) was done by using MATLAB software (MATLAB - version 2006) on the oil production rate in simulated VAPEX processes by using a CMG simulator (CMG - version 2006 from Computer Modeling Group), for conventional and nano-assisted VAPEX processes. The results of the ANOVA test are:

- A significant difference between the nano-assisted VAPEX and the conventional VAPEX was indicated. It showed that differences in oil production between the two methods were not affected by random errors during the experiments such as uneven mixing of MMTs, the fluctuation of solvent pressure, temperature, or random asphaltene precipitation and deposition. The significant difference between the two methods elucidated that MMTs are able to change the matrix heterogeneity. 
- There was no difference between the simulated VAPEX and the conventional VAPEX. This confirmed the accuracy of the simulated model and revealed that the simulated VAPEX and conventional VAPEX processes were matched.

In addition, according to Darcy's equation (Eq. 1), the production rate is dependent on the interfacial surface area, the viscosity, etc.

$$
Q=\frac{k A}{\mu} \frac{\Delta P}{L}
$$

where $\mathrm{Q}$ denotes the flow rate of the produced oil, A presents the interfacial surface area, and $k$ and $\mu$ are the matrix permeability and the fluid viscosity, respectively. The term $\Delta P / L$ shows the pressure gradient along with the length of the matrix.

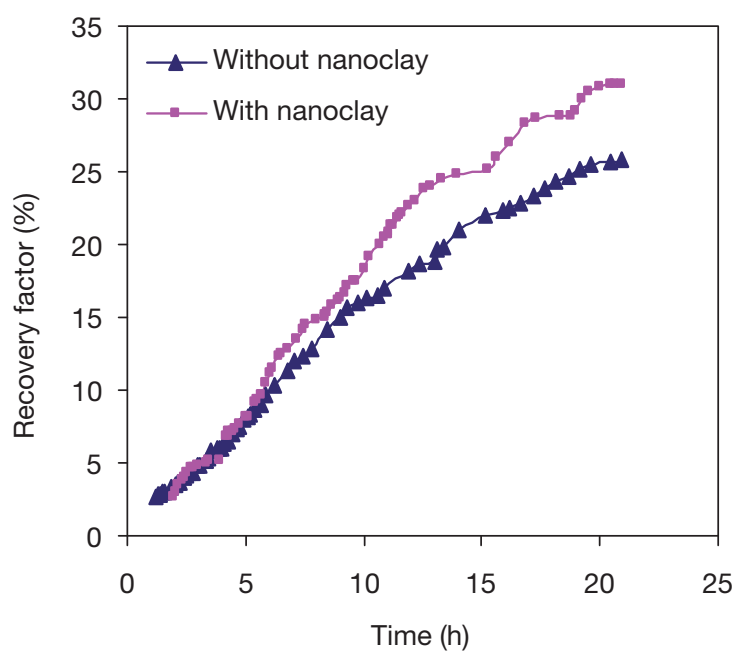

Figure 14

Recovery factor in the presence and absent of MMTs in the VAPEX process.

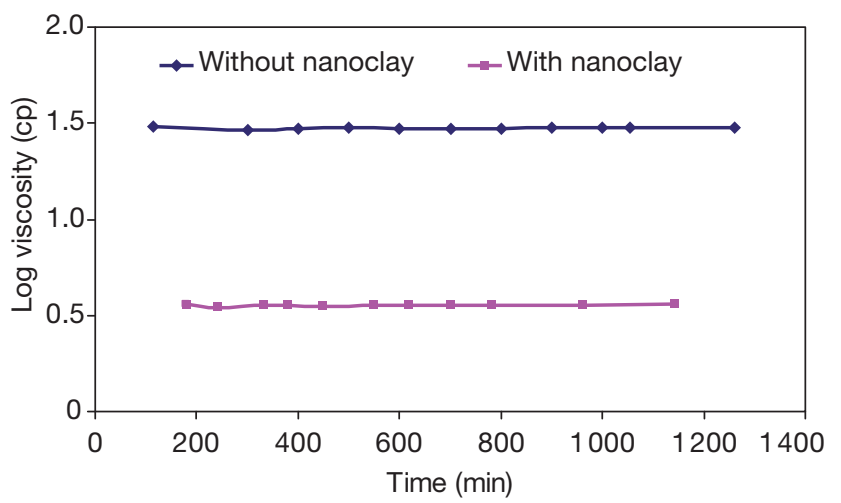

Figure 15

The measured viscosity of produced oil versus the run time in conventional and nano-assisted experiments.
In the nano-assisted VAPEX model, not only did the interfacial area increase (for the sake of breakthrough), but the heavy oil viscosity also decreased (for the sake of asphaltene transfer from the oil media into the interlayer spaces of MMTs).

The viscosity of the produced live oil was measured experimentally using an online high-pressure capillary viscometer, which is represented in Figure 7. Figure 15 depicts the viscosity of the produced oil versus the run time. As can be observed from this figure and according to the reasons mentioned above, the MMT nanoclays markedly reduced the oil viscosity.

Therefore, the production rate increased. Moreover, the specific gravity of MMTs is more than heavy oil. After adsorption of asphaltene into the MMTs (intercalation), this difference was even more, and this led to improving the live oil gravity drainage via convectional mass transfer. This led to enhancing the production rate and the recovery factor.

\subsection{Solvent Consumption}

Breakthrough is a dynamic phenomenon that forms in twophase systems. The solvent chamber/bitumen system in the VAPEX process is prone to breakthrough formation. During this phenomenon, a part of the injected vapor was lost through the separator without dilution of bitumen. Therefore, the in situ solvent was considered to be distributed in two media; one, which had diffused into the heavy oil, and the other, which was trapped in the pore volumes of the swept zone. The ratio of dissolution efficiency was defined as the rate of dissolved solvent to the rate of injected solvent. The experimental results revealed that the ratio of the dissolved solvent to the injected solvent in the nano-assisted VAPEX method is more than the conventional VAPEX method. Figure 16 shows the comparative diagram of dissolution efficiency for nano-assisted and conventional VAPEX processes.

The MMT's form enhanced breakthrough with a high aspect ratio to increase the vapor diffusion and the bitumen dilution.

Adsorption of asphaltene particles in the MMT's structure led to reducing the asphaltene deposition on the matrix surfaces. The wettability of the matrix did not shift to oil-wet conditions and the permeability remained constant.

Moreover, intercalation of asphaltenes into the MMTs reduced the oil viscosity, enhanced the gravity drainage, increased the falling rate of live oil, and expanded the interfacial area between the original oil and the vapor chamber. According to the hypothesis of surface renewal, the concentration gradient between the solvent and the heavy oil was increased. This led to increasing the solvent diffusion into the heavy oil as well as the effective consumption of the solvent. 


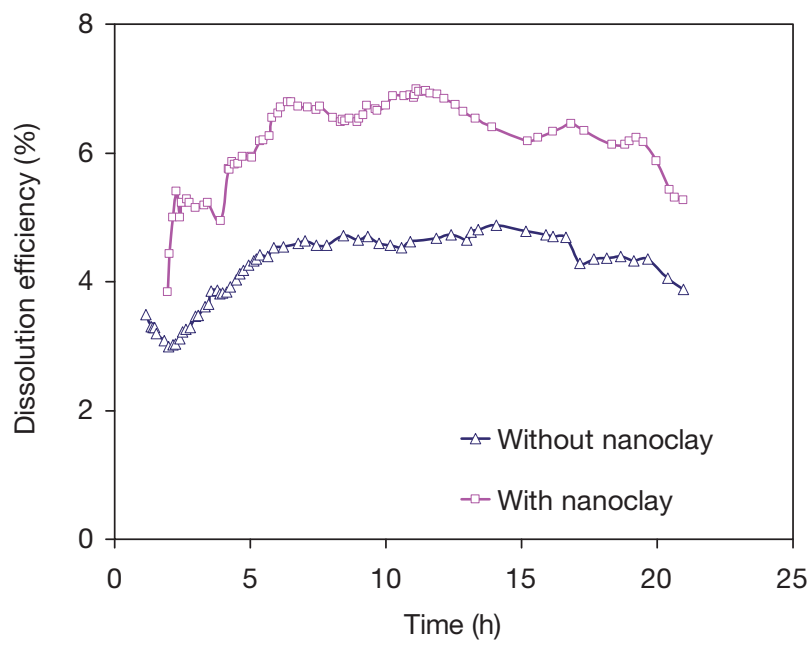

Figure 16

Dissolution efficiency in the presence and absent of MMTs in the VAPEX process.

\section{RECOMMENDATIONS FOR INJECTING THE MMT NANOCLAYS}

There are some restrictions in selecting the carrier to move the MMT particles from the wellhead to the bottom hole; in the case of MMTs, water is not a suitable carrier, because of the clay swelling. Reduction of carrier viscosity leads to more penetration of the carrier and nanoparticles into the reservoir media and the greater efficiency of the process. Nowadays, some technical methods, such as Coiled Tubing (CT) and a bullhead (BH), are used for acid and hydraulic oil injection into the reservoirs. Injection of nanoparticles into the reservoir can be done via both the solvent injection wells and the live oil production wells by $\mathrm{CT}$ or $\mathrm{BH}$ methods.

\section{CONCLUSIONS}

Quantitative and qualitative analysis of remaining heavy oil asphaltenes and resins in the VAPEX matrix was carried out by TG and DTA methods, respectively. The high content of precipitated asphaltenes and resins in the nano-assisted matrix revealed that asphaltenes and resins were markedly adsorbed into the MMT's interlayer spaces. Distributions of asphaltenes and resins were not uniform in the swept zone and their concentration around the injection well was maximum, while around the production well and both sides it was minimum. Moreover, the ANOVA test showed a significant difference between the nano-assisted VAPEX and the conventional VAPEX. The difference in the oil production rate between the two methods was not affected by random errors during the experiments. It elucidated that MMTs were able to change the matrix heterogeneity. The greater oil recovery and more effective consumption of solvent $(30 \pm 4 \%)$ using MMTs were directly related to the greater contact areas formed by formation of more breakthroughs, adsorption of asphaltenes into the MMT's interlayer spaces and reduction of oil viscosity.

\section{ACKNOWLEDGEMENTS}

The assistance of Mr. Salimi, the PUT technician, as well as Miss Mahdavi in carrying out the experiments is appreciated. The authors also thank Dr. Nasr Esfahany (Isfahan University of Technology), Prof. Rashidi (Amirkabir University of Technology) and Dr. Torabi (The University of Tehran) for their valuable comments in preparing this paper. Furthermore, the financial supports of Islamic Azad University (Shahreza Branch) and Iran Nanotechnology Initiative Council are gratefully acknowledged.

\section{REFERENCES}

1 Pourabdollah K., Zarringhalam Moghaddam A., Kharrat R., Mokhtari B. (2010) Study of Asphaltene and Metal Upgrading in VAPEX Process, Energ. Fuel. 24, 8, 4396-4401.

2 Altunina L.K., Kuvshinov V.A. (2008) Improved Oil Recovery of High-Viscosity Oil Pools with Physicochemical Methods and Thermal-Steam Treatments, Oil Gas Sci. Technol. 63, 1, 37-48.

3 Golovko Y., Gorbunova L., Kamyanov V., Pevneva G., Filimonova T. (2008) Principal Regularities in Compositions and Structures of High-Molecular Compounds from Crude Oils and Natural Bitumens, Oil Gas Sci. Technol. 63, 1, 95-114.

4 Hénaut I., Argillier J.F. (2004) Pipeline Transportation of Heavy Oils, a Strategic, Economic and Technological Challenge, Oil Gas Sci. Technol. 59, 5, 455-466.

5 Shu W.R. (1984) A viscosity correlation for mixtures of heavy oil, bitumen, and petroleum fractions, Soc. Pet. Eng. J. 24, 3, 277-282.

6 Karoussi O.L., Skovbjerg L., Hassenkam T., Svane-Stipp S.L., Hamouda A.A. (2008) AFM Study of Calcite Surface Exposed to Stearic and Heptanoic Acids, Colloid. Surface. A 325, 107-122.

7 Kasevich R.S. (2008) Method and apparatus for in-situ radiofrequency assisted gravity drainage of oil (RAGD), US Patent 7441597.

8 Abu-Khader M.M., Speight J.G. (2007) Influence of high asphaltene Feedstock on processing, Oil Gas Sci. Technol. 62, 715-722.

9 Mousavi-Dehghani S.A., Vafaie-Sefti M., Mirzayi B., Fasih M. (2007) Experimental Investigation on Asphaltene Deposition, in Porous Media during Miscible Gas Injection, Iran. J. Chem. Chem. Eng. 26, 4, 39-48.

10 Das S.K., Butler R.M. (1994) Vapor Extraction of Heavy Oil and Bitumen: A Review, J. Can. Petrol. Technol. 33, 39-45.

11 Kök M.V., Yildirim Y., Akin S. (2009) Application of Vapor Extraction (VAPEX) Process on Carbonate Reservoirs, Energy Sources, Part A. 31, 377-386.

12 Johnson J.R., Koros W.J. (2009) Utilization of nanoplatelets in organic-inorganic hybrid separation materials: Separation advantages and formation challenges, Taiwan Institute Chem. Eng. J. 40, 268-275. 
13 Joshi G.V., Kevadiya B.D., Patel H.A., Bajaj H.C., Jasra R.V. (2009) Montmorillonite as a Drug Delivedry System: Intercalation and in Vitro Release of Timolol Maleate, Pharmaceutics 374, 53-57.

14 Masih D., Izumi Y., Aika K., Seida Y. (2007) Optimization of an Iron Intercalated Montmorillonite Preparation for the Removal of Arsenic at Low Concentrations, Eng. Life Sci. 7, 52-60.

15 Stathi P., Papadas I.T., Enotiadis A.R., Gengler Y.N., Gournis D., Rudolf P., Deligiannakis Y. (2009) Effects of Acetate on Cation Exchange Capacity of a Zn-Containing Montmorillonite. Physicochemical Significance and Metal Uptake, Langmuir 25, 6825-6833.

16 Navratilova Z., Wojtowicz P., Vaculikova L., Sugarkova V. (2007) Sorption of Alkylammonium Cations on Montmorillonite, Acta Geodyn. Geomater. 4, 59-65.

17 Fusova L. (2009) Modification of the Structure of CaMontmorillonite Modifikace Struktury Ca-Montmorillonitu, Geo. Sci. Eng. LV, 27-32.

18 Patel H.A., Somani R.S., Bajaj H.C., Jasra R.V. (2006) Nanoclays for Polymer Nanocomposites, Paints, Inks, Greases and Cosmetics Formulations, Drug Delivery Vehicle and Waste Water Treatment, B. Mater. Sci. 29, 133-145.

19 Lin J.J., Wei J.C., Juang T.Y., Tsai W.C. (2007) Preparation of Protein-Silicate Hybrids from Polyamine Intercalation of Layered Montmorillonite, Langmuir 23, 1995-1999.

20 Rahman Z.A., Hamzah U., Ahmad N. (2010) Geotechnical characteristics of oil-contaminated granitic and metasedimentary soils, Asian J. Appl. Sci. 3, 237-249.
21 Pourabdollah K. (2010) Modeling and Optimization of VAPEX Process in Fractured Reservoirs, PhD Thesis, Tarbiat Modares University, Tehran, Iran.

22 Shishkin Y.L. (2006) Scanning Calorimetry and Thermogravimetry in Analysis of Petroleum Systems. Determination of the Component Composition, Chem. Technol. Fuels Oils 42, 4, 300-307.

23 Ali M.A., Siddiqui M.A.B., Zaidi S.M.J. (1998) Thermal Analysis of Crude Oils and Comparison with SIMDIST and TBP Distillation Data, Therm. Anal. 51, 307-319.

24 Kök M.V. (1999) Feasibility study of crude oil fields by thermal analysis technique, J. Therm. Anal. Calorim . 56, 947-951.

25 Kök M.V., Karacan O., Pamir R. (1998) Kinetic Analysis of Oxidation Behavior of Crude Oil SARA Constituents, Energ. Fuel. 12, 3, 580-588.

26 Karacan O., Kök M.V. (1997) Pyrolysis Analysis of Crude Oils and Their Fractions, Energ. Fuel. 11, 2, 385-391.

27 Kök M.V., Okandan E. (1994) Thermal analysis of crude oillignite mixtures by differential scanning calorimetry, Fuel 73, 4, 500-504. 